\title{
Karla Grierson, Discours d'Auschwitz. Littérarité, représentation, symbolisation
}

\section{Emanuele Kanceff}

\section{Q OpenEdition}

1 Journals

\section{Edizione digitale}

URL: http://journals.openedition.org/studifrancesi/35087

DOI: 10.4000/studifrancesi.35087

ISSN: 2421-5856

\section{Editore}

Rosenberg \& Sellier

\section{Edizione cartacea}

Data di pubblicazione: 1 novembre 2005

Paginazione: 445

ISSN: 0039-2944

\section{Notizia bibliografica digitale}

Emanuele Kanceff, «Karla Grierson, Discours d'Auschwitz. Littérarité, représentation, symbolisation», Studi Francesi [Online], 146 (XLIX | II) | 2005, online dal 30 novembre 2015, consultato il 20 avril 2021. URL: http://journals.openedition.org/studifrancesi/35087; DOI: https://doi.org/10.4000/studifrancesi. 35087

Questo documento è stato generato automaticamente il 20 avril 2021.

\section{(c) (1)}

Studi Francesi è distribuita con Licenza Creative Commons Attribuzione - Non commerciale - Non opere derivate 4.0 Internazionale. 


\title{
Karla Grierson, Discours d'Auschwitz. Littérarité, représentation, symbolisation
}

\author{
Emanuele Kanceff
}

\section{NOTIZIA}

KARLA GRIERSON, Discours d'Auschwitz. Littérarité, représentation, symbolisation, Paris, Champion, 2003, 528 pp.

1 Immaginate letteralmente le centinaia di libri che evocano di prima mano $\mathrm{i}$ fatti fra $\mathrm{i}$ più efferati nella storia dell'umanità. Poi immaginate che, tranne qualche rara eccezione, non li legga nessuno e che gli istituti culturali ignorino la loro presenza nelle loro biblioteche e nei loro archivi. Immaginate ancora che gli stessi istituti culturali producano, direttamente o indirettamente, centinaia di altri libri e articoli che evocano gli stessi fatti efferati, ma che nello stesso tempo affermano che sarebbe meglio non parlarne, che sarebbe preferibile il silenzio su questi fatti.

Uno studio di «estetica della ricezione» nel senso letterario del termine è pressoché impossibile nel caso di questi scritti, che noi chiamiamo racconti delle deportazioni, per la semplice ragione che, a parte pochi esempi, i testi autobiografici dei deportati non sono considerati come testi letterari o "estetici», e non hanno beneficiato di una vera ricezione da parte dei lettori, critici o dal "grande pubblico». Questa situazione non è stata migliorata da carattere contemporaneo di questi racconti, di cui i più vecchi sono del 1945 e i più recenti sono di qualche mese o di qualche settimana fa. Che le si accetti o no queste ipotesi epistemologiche, bisogna riconoscere l'urgenza di una situazione materiale. Gli ultimi sopravvissuti della deportazione o del genocidio oggi sono relativamente anziani: tra trenta o quarant'anni, non ci sarà più nessuno che racconterà di prima persona l'estensione potenziale e l'auto-distruzione umana. Non è venuto il momento di ascoltare e di leggere quello che i sopravvissuti hanno da dire, e 
di rifletterci sopra, senza sentirci obbligati di coprire questa vergogna evocando il «silenzio» d'«Auschwitz» Non esiste un deportato «tra tutti», e l'inchiesta intellettuale acquista tutto il suo significato, la sua ampiezza e la sua difficoltà grazie a questa presa di coscienza. Anche i testi più poveri dal punto di vista stilistico tra i racconti di deportazione, considerati abitualmente come «non letterari», non sono generici: la scrittura «tramite altri» non esiste.

3 Si può pensare che il silenzio rispettoso è la sola risposta critica degna di questi scritti, ma ognuno sceglie il suo modo per stare zitto. Realizzando il lavoro d'interpretazione, leggendo gli scritti di una sopravvissuta, le reazioni emotive possono obbligarci da un momento all'altro a interrompere la lettura e a chiudere il libro: se noi esponiamo i frutti dell'analisi, noi teniamo le nostre emozioni dentro. Ricordiamo Primo Levi a proposito del dolore, che fu per lui «[?] la seule force qui se crée de rien, sans dépense et sans fatigue. Il suffit de ne pas voir, ne ne pas écouter, ne pas faire».

4 La goffaggine ermeneutica è meno grave dell'indifferenza: spetta al lettore giudicare.

5 Se noi consideriamo il racconto della deportazione come un testo narravivo che riporta l'internamento del suo autore lontano dal suo domicilio (sovente all'estero), dobbiamo prima di tutto precisare di quale internamento si tratta nel quadro dei racconti studiati. In altri termini, lo statuto del racconto di deportazione in quanto scritto non di finzione, presuppone il riconoscimento del contesto a cui esso riporta, anche se possono esserci elementi creativi durante la stesione dello scritto. L'attenersi strettamente ai fatti dell'esperienza vissuta, ma anche il superamento di una storia personale o privata, implica la presa di coscienza di fatti riconosciuti di interesse pubblico, chiamati comunemente la Storia.

6 L'episodio storico che ci interessa qui è evidentemente quello del regime nazionalsocialista tedesco e dell'internamento di intere popolazioni di civili che ha attuato durane la Seconda Guerra Mondiale. Ma perché esaminare i racconti dei deportati di Auschwitz piuttosto di quelli di Buchenwald, di Dachau o di tutti gli altri centri di deportazioni hitleriani?

7 Fino agli anni Novanta, gli scritti autobiografici della deportazione e del genocidio di Hitler furono in gran misura messi al bando intellettuale in Europa: gli scritti evocavano gi avvenimenti di Auschwitz riferendosi ben poco, a volte per niente, alle persone che le avevano vissute, sotto il pretesto che si doveva mantenere un «silenzio» rispettoso per questi fatti.

Questa situazione è attuale, perché se «l'indicibile» di questi avvenimenti estremi non viene accettata oggi che sono passati pochi anni dai fatti, apparirà ancora sotto delle forme sottili, ad esempio la "surfocalisation» di qualche attore e l'autore è forse, paradossalmente, uno degli assi maggiori. (I recenti studi europei sui racconti di deportazione portano ad un numero di scrittori conosciuti: Primo Levi, Robert Antelme, Charlotte Delbo, come fu il caso risalente a dieci o venti anni fa di Elie Wiesel nell'America del nord).

9 È in questo contesto in cui si inserisce lo studio sistematico degli schemi di scrittura di una cinquantina di racconti di vita (in lingua francese, inglese, tedesca e italiana) di persone sopravvissute alla deportazione di Auschwitz. L'esame della rappresentazione e, ad un livello superiore, delle vocazioni simboliche della scrittura, sostenuto dai rapporti di numerosi altri racconti, e confrontato con i discorsi critici di tutte le discipline, suggerisce che le rivendicazioni del «silenzio» o dell' «indicibile» non 
venivano dall'angoscia dei deportati ma da quelle dei commentatori. La memoria della deportazione sovente si costruisce in assenza dei superstiti, a tal punto che ci si potrebbe domandare se il mito di Auschwitz interamente simbolizzato (dall'esterno) e simbolico, non ha annullato la diversità delle realtà e delle persone di cui si è andato a rappresentare, gli incidenti ridotti a delle «tragedie» e gli esseri a delle «vittime».

L'esperienza di Auschwitz fa parte dell'esperienza umana, e il superstite può essere anche un narratore. 